\title{
Smartphone-Based Digital KWH Meter and SMS Gateway in Residential Homes
}

\section{Rancang Bangun KWH Meter Digital Berbasis Smartphone dan SMSGateway Pada Rumah Hunian}

\author{
Moh.Muzakki Firmansyah ${ }^{1}$, Akhmad Ahfas ${ }^{2}$, Syamsudduha Syahrorini $^{3}$, Dwi Hadidjaja R.S ${ }^{4}$ \\ \{muzakki.firman20@gmail.com ${ }^{1}$, ahfas@umsida.ac.id ${ }^{2}$,syahrorini@umsida.ac.id ${ }^{3}$,dwihadidjaja@umsida.ac.id ${ }^{4}$ \}
}

Program Studi Teknik Elektro, Fakultas Sains dan Teknologi, Universitas Muhammadiyah Sidoarjo

\begin{abstract}
Consumers need to be conscious of electrical energy usage every day, in accordance with the need for powerconsumption. Then a kWHmeter is needed that will provide this data so that people can handle it. This study developed a kWHmeter that can show Smartphone voltage, current, fuel, overall usage and projected electricity costs and can submit alerts when electricity use is near to a preset limit using the SDM230 Modbus, Arduino Uno, NodeMCU ESP8266, GSM module, MySQL database. In this research, with a precision of $98.704 \%$ for voltage, $39.88 \%$ for current, $53.333 \%$ for energy usage, and $26.14 \%$ for power energy, test results of the instrument can be operated veryeffectively. The method will also submit SMS alerts with an average speed of 0.6 seconds for this analysis and the android program is made to show data on the 100\% accuracy of energy usage and $99.508 \%$ accuracy of cost estimates.
\end{abstract}

Keywords - kWHmeter; SDM230 Modbus; Arduino Uno; Internet of Things; Short Message Service; Database

\begin{abstract}
Abstrak. Konsumen perlu mengetahui jumlah pemakaian energi listrik yang dibutuhkan setiap harinya. Maka dibutuhkan kWHmeter yang dapat memberikan informasi tersebut, sehingga dapat mengelolah pemakaaian energi. Penelitian ini mendesain kWHmeter yang dapat menampilakan Tegangan, Arus, Daya, Jumlah Konsumsi dan Perkiraan Biaya Listrik melalui Smartphone (menggunakan sensor energi SDM230 dan Android Studio) dan dapat mengirim notifikasi SMS (SIM800L) jika penggunaan energi listrik mendekati target kemudian penyimpanan data (Database MySQL). Pada penelitian ini hasil pengujian alat dapat beroperasi dengan cukup efisien dengan presentasi akurasi sebesar 98,704\% pada pengukuran Tegangan, 39,88\% pada pengukuran Arus, 53,333\% pada pengukuran jumlah konsumsi energi, dan 26,141\% pada pengukuran Daya. Pada penelitian ini alat juga dapat mengirimkan notifikasi SMS dengan kecepatan rata rata 0,6 detik dan aplikasi android yang dibuat dapat menampilkan informasijumlah konsumsi energi listrik dengan akurasi 100\% serta perkiraan biaya dengan akurasi 99,508\%.
\end{abstract}

Kata Kunci-kWHmeter; SDM230 Modbus; Arduino Uno; Internet of Things; Short Message Service; Database

\section{Pendahuluan}

Kebutuhan listrik semakin meningkat dari tahun ke tahun, bulan ke bulan dan minggu ke minggu, hal ini dikarenakan pembuatan produk produk yang menggunakan energi listrik sebagai energinya juga gencar dikeluarkan oleh produsen elektronik sehingga kebutuhan akan listrik sudah menjadi kebutuhan yang sangat penting untuk semua konsumen[1]. Kemudian naiknya biaya listrik atau yang biasa disebut Tarif Dasar Listrik (TDL) yang terjadi setiap tahunnya membuat para konsumen untuk lebih bijak dalam menggunakan energi listrik[2].

Maka dari itu pada tugas akhir ini dibuat sebuah energi meter yang dapat memonitoring jumlah konsumsi energi listrik beserta dengan perkiraan biaya. Pada alat ini juga menampilkan informasi tentang tegangan, arus, dan daya listrik. Dengan menggunakan sensor Eastron SDM230 Modbus, Mikrokontroller, Internet of Things yang dapat memungkinkan alat mengirim data pada server sehingga data dapat dilihat melalui aplikasi smartphone. Pada alat ini juga dilengkapi dengan notifikasi Short Message Service (SMS) yang aktif pada saat Perkiraan Biaya Listrik melebihi target.

Sistem kerja dari energi meter ini adalah Sensor Eastron SDM230 Modbus akan membaca nilai satuan listrik dan menghitung jumlah konsumsi energi listrik, melalui komunikasi modbus kemudian data dibaca oleh mikrokontroller Arduino Uno. Pada mikrokontroller ini data di olah sehingga dapat menampilkan nilai perkiraan biaya yang dipakai untuk mengatur Batasan biaya sehingga jika biaya melebihi target SIM800L akan aktif dan notifikasi SMS dapat dikirim ke nomor telpon pengguna. Kemudian data pada Arduino Uno akan dikirim ke mikrokontroller NodeMCU menggunakan serial communication dan data tersebut dikirim ke server thingspeak. Dari server thingspeakkemudian data ditampilkan pada sebuah website weebly agar dapat terlihat pada aplikasi smartphone. Aplikasi tersebut bernama SKRIPSIMUZ yang dibuat menggunakan Android Studio dengan prinsip system webview. 


\section{METODE}

\section{A. Perancangan sistem (diagram blok sistem)}

Berdasarkan diagram blok sistem (Gambar 1), dijelaskan bahwa listrik melewati sensor energi meter Eastron SD230 kemudian diproses pada mikrokontroller Arduino Uno yang terhubung pada modul internet NodeMCU. Monitoring hasil dari pembacaan sensor akan melalui server kemudian bisa ditampilkan pada aplikasi android pada smartphone. Notifikasi SMS akan dilewatkan Modul SIM800L. Perancangan dan pembuatan KWH Meter Digital Dengan Informasi Tegangan, Arus, Daya, Jumlah Konsumsi Energi Listrik Dan Perkiraan Biaya Tagihan Monitoring Smartphone Secara Realtime Dan Notifikasi Short Message Service (SMS) pada Rumah Hunian meliputi software dan hardware, antara lain:

1. Energi Listrik sebagai objek yang akan diukur oleh Eastron SDM230. Energi listrik akan melalui sensor sebelumdihubungkan ke seluruh perangkat elektronik di rumah hunian.

2. Eastron SDM230 Modbus sebagai sensor untuk mengukur energi listrik yang digunakan. Dalam pemasangannya,sensor akan terhubung secara seri dengan energi listrik.

3. Arduino Uno sebagai kontrol atau pusat kendali dari semua input dan output yang digunakan. Arduino Uno terhubung dengan ESP8266 agar dapat mengirim data pada server sehingga data dapat ditampilkan pada aplikasiandroid yang terhubung dengan internet.

4. NodeMCU ESP8266 sebagai sistem proses Internet of Things (IoT), yaitu perangkat yang dapat menghubungkanproses yang telah dikelola oleh Arduino Uno terhubung dengan internet.

5. SIM800L sebagai proses pengolah Short Message Service (SMS). Notifikasi SMS akan diberikan ketika pemakaian energi listrik sudah melebihi target yang ditetapkan.

6. Server adalah penghubung antara data sensor dan database untuk ditampilkan pada aplikasi android.

7. Database MySQL sebagai penyimpan data sensor.

8. Aplikasi Android sebagai media penampil dan kontrol interface hasil dari pembacaan sensor.

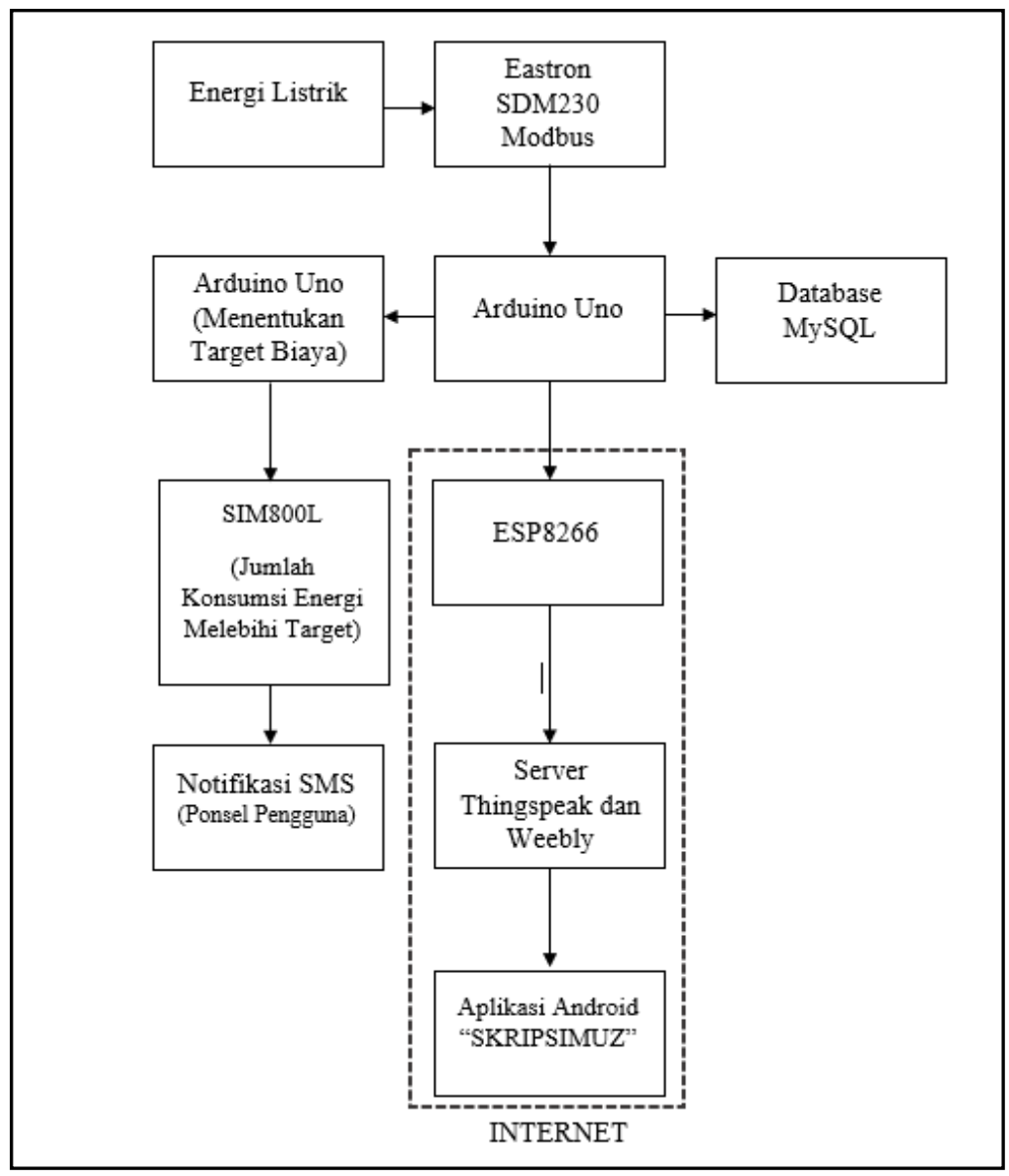

Gambar 1. Diagram Blok Sistem 


\section{B. Algoritma dan diagram alur sistem}

Gambar 2. Menjelaskan bahwa alur kerja sistem dimulai dengan menginisialisasi Arduino setelah itu Arduino membaca sensor energi meter, kemudian diproses dengan menampilakan hasil pembacaan pada aplikasi android pada smartphone. Pada pembatasan target pemakaian energi listrik jika target melebihi batas yang sudah ditentukan maka akan ada notifikasi yang dikirim melalui Short Message Service (SMS). Berdasarkan diagram alir sistem dapat dijelaskan bahwa:

1. Sistem dimulai dengan masuknya energi listrik pada alat di penelitian ini.

2. Kemudian energi listrik yang keluar diukur dan diproses pada Arduino Uno.

3. Hasil pengukuran yang telah di proses pada Arduino Uno di tampilkan pada Aplikasi Android Smartphone.

4. Pada pembatasan konsumsi energi listrik jika pemakaian melebihi target maka akan dikirim notifikasi melaluiShort Message Service (SMS).

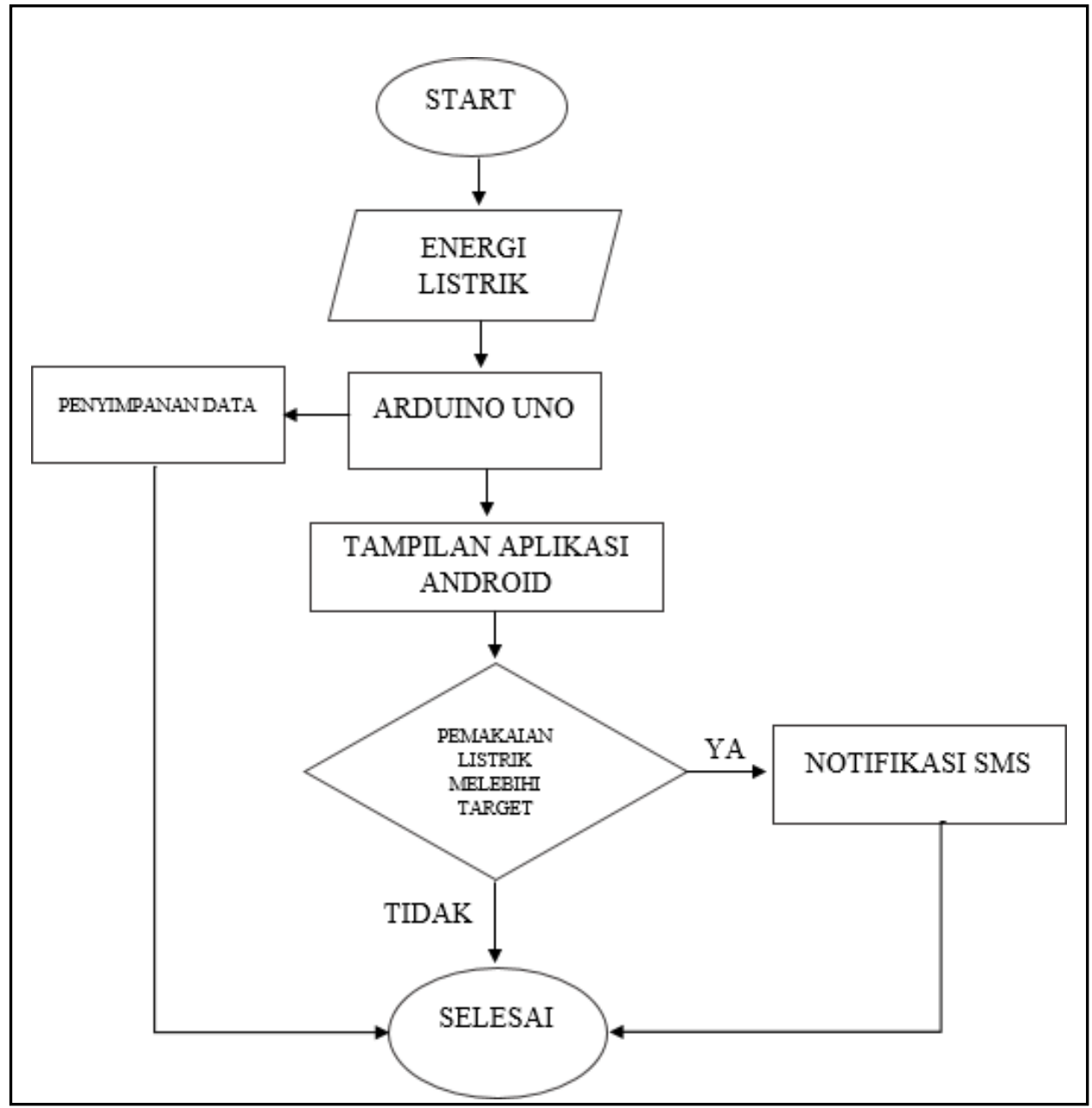

Gambar 2. Diagram Alur atau Flowchart Sistem

\section{HASil dan Pembahasan}

Gambar rangkaian di atas menggunakan Software Adobe Coreldraw. Software tersebut dipilih karena memudahkan dalam desain dan tidak perlu menambahakan library komponen. Selain itu Coreldraw tidak dapat mensimulasikan rangkaian karena software hanya berbasis desain grafis. 


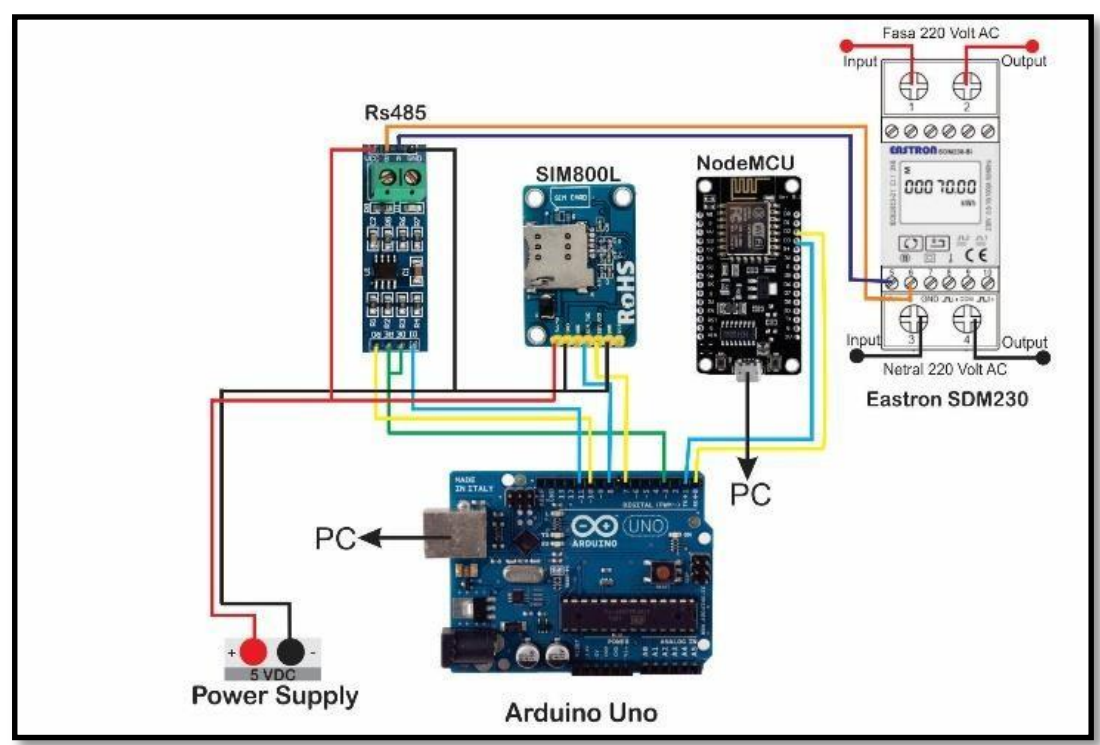

Gambar 3. Desain Rangkaian

Desain mekanik (gambar 3) menggunakan panel listrik ukuran lebar $40 \mathrm{~cm}$, panjang $50 \mathrm{~cm}$, lebar $20 \mathrm{~cm}$ dan papan kayu ukuran panjang $200 \mathrm{~cm}$ dan lebar $150 \mathrm{~cm}$. Pada panel listrik berisi rangkaian yang diteliti antara lain SDM230, RS485, Arduino Uno, NodeMCU, SIM800L, dan power supply. Pada papan kayu berisi rangkaian pengujian antara lain $\mathrm{kWH}$ meter, amperemeter, voltmeter, stop kontak, fitting lampu dan MCB (Miniatur Circuit Breaker). Pada gambar 4 terdapat beberapa bagian yaitu :

1. Panel listrik.

2. Papan kayu tempat rangkaian pengujian.

3. Soket terminal input sumber listrik AC.

4. MCB (Miniatur Circuit Breaker).

5. kWH Meter.

6. Soket terminal output sumber listrik AC.

7. Voltmeter dan Amperemeter.

8. Fitting Lampu.

9. Stopkontak.

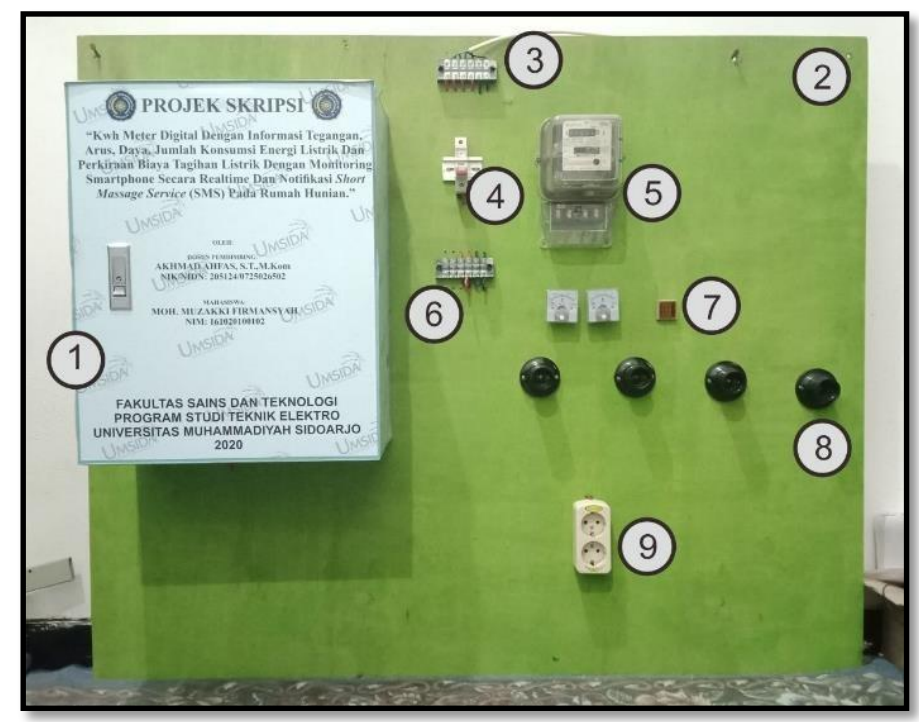

Gambar 4. Desain Mekanik 
Pengujian dilakukan yaitu untuk mengetahui cara kerja dan prinsip alat yang telah dibuat dan dirangkai apakah sudah sesuai atau tidak sesuai dengan perencanaan awalnya. Pengambilan data dan pengujian dilakukan pada setiap bagian hingga dalam keseluruhan sistem. Pengujian setiap bagian tersebut terdiri dari pengujian energi meter (Eastron SDM230 Modbus), pengujian Notifikasi SMS, pengujian Tampilan pada aplikasi Smartphone, serta pengujian perhitungan biaya pemakaian energi listrik.

\section{A. Pengujian energi meter (eastron sdm230 modbus)}

Pengujian Energi meter dimaksud untuk mengetahui ketepatan sensor dalam membaca satuan dan pemakaian energi listrik dengan akurat membandingkan dengan Voltmeter, Amperemeter, kWH Meter, dan rumus menghitung kilowatt per-hour. Pengujian SDM230 bertujuan untuk apakah sensor dapat bekerja secara optimal.

Tabel 4.1 Hasil Pengujian Nilai Tegangan SDM230

\begin{tabular}{cccc}
\hline No. & Parameter atau Alat Ukur & Hasil & Akurasi \\
\hline $\mathbf{1}$ & Voltmeter Digital & 196,6 volt & \multirow{2}{*}{$98,704 \%$} \\
$\mathbf{2}$ & Eastron SDM230 & 194,06 volt & \\
\hline
\end{tabular}

Pada Tabel 4.1 nilai ketepatan atau akurasi pada hasil percobaan menggunakan sensor SDM230 sebesar 98,704\%. Sehingga dapat disimpulkan bahwa sensor SDM230 tersebut dapat bekerja dan berfungsi dengan baik dalam pembacaan nilai tegangan.

Tabel 4.2 Hasil Pengujian Nilai Arus SDM230

\begin{tabular}{cccc}
\hline No. & Parameter atau Alat Ukur & Hasil & Akurasi \\
\hline $\mathbf{1}$ & Amperemeter Digital & 1,92 ampere & \multirow{2}{*}{$39,88 \%$} \\
$\mathbf{2}$ & Eastron SDM230 & 0,76 ampere & \\
\hline
\end{tabular}

Pada tabel 4.2 nilai ketepatan atau akurasi pada hasil percobaan menggunakan sensor SDM230 sebesar 39,88\%. Sehingga dapat disimpulkan bahwa sensor SDM230 tersebut dapat bekerja dan berfungsi dengan kurangbaik dalam pembacaan nilai arus.

Tabel 4.3 Hasil Pengujian Jumlah Konsumsi Energi SDM230

\begin{tabular}{cccc}
\hline No. & Parameter atau Alat Ukur & Hasil & Akurasi \\
\hline $\mathbf{1}$ & kWH Meter Analog & $0,03 \mathrm{kWH}$ & \multirow{2}{*}{$53,33 \%$} \\
$\mathbf{2}$ & Eastron SDM230 & $0,016 \mathrm{kWH}$ & \\
\hline
\end{tabular}

Pada Tabel 4.3 nilai ketepatan atau akurasi pada hasil percobaan menggunakn sensor SDM230 sebesar 53,333\%. Sehingga dapat disimpulkan bahwa sensor SDM230 tersebut dapat bekerja dan berfungsi dengan cukup baik dalam pembacaan nilai jumlah konsumsi energi.

Tabel 4.4 Hasil Pengujian Nilai Daya SDM230

\begin{tabular}{cccc}
\hline No. & Parameter atau Alat Ukur & Hasil & Akurasi \\
\hline $\mathbf{1}$ & Rumus Daya & 377,64 watt & $26,141 \%$ \\
$\mathbf{2}$ & Eastron SDM230 & 98,4 watt & \\
\hline
\end{tabular}

Pada Tabel 4.4 nilai ketepatan atau akurasi pada hasil percobaan menggunakan sensor SDM230 sebesar $26,141 \%$. Sehingga dapat disimpulkan bahwa sensor SDM230 tersebut dapat bekerja dan berfungsi dengan kurang baik dalam pembacaan nilai daya.

Tabel 4.5 Hasil Pengujian Jumlah Konsumsi Energi SDM230

\begin{tabular}{cccc}
\hline No. & Parameter atau Alat Ukur & Hasil & Akurasi \\
\hline $\mathbf{1}$ & Rumus jumlah energi & $0,0628 \mathrm{kWH}$ & \multirow{2}{*}{$25,94 \%$} \\
$\mathbf{2}$ & Eastron SDM230 & $0,016 \mathrm{kWH}$ & \\
\hline
\end{tabular}


Pada Tabel 4.5 nilai ketepatan atau akurasi pada hasil percobaan menggunakn sensor SDM230 sebesar 25,94 $\%$. Sehingga dapat disimpulkan bahwa sensor SDM230 tersebut dapat bekerja dan berfungsi dengan kurang baik dalam pembacaan nilai jumlah konsumsi energi.

\section{B. Pengujian notifikasi short message service (sms)}

Pengujian Notifikasi Short Message Service (SMS) ini bertujuan untuk mengetahui bahwa alat dapat mengirim notifikasi lewat SMS dengan optimal. Pada pengujian ini menggunakan metode perbandingan kecepatan waktu diterimanya SMS ke Smartphone pengguna. Dengan menetapkan nilai batas biaya listrik, jika melebihi target batas yang ditentukan maka seharusnya SMS dapat dikirim kemudian diterima.

Tabel 4.7 Hasil Pengujian Notifikasi SMS

\begin{tabular}{ccccc}
\hline $\begin{array}{c}\text { Percobaan } \\
\text { ke- }\end{array}$ & $\begin{array}{c}\text { Target } \\
\text { (Rupiah) }\end{array}$ & $\begin{array}{c}\text { Keterangan waktu pada } \\
\text { saat melebihi batas } \\
\text { target (WIB) }\end{array}$ & $\begin{array}{c}\text { Keterangan waktu } \\
\text { pada saat Notifikasi } \\
\text { SMS diterima (WIB) }\end{array}$ & $\begin{array}{c}\text { Selisih } \\
\text { waktu } \\
\text { (Detik) }\end{array}$ \\
\hline $\mathbf{1}$ & Rp7.900 & 07.13 & 07.14 & 1 \\
$\mathbf{2}$ & Rp8.300 & 07.33 & 07.33 & 0 \\
$\mathbf{3}$ & Rp8.500 & 07.42 & 07.43 & 1 \\
$\mathbf{4}$ & Rp8.700 & 07.52 & 07.53 & 1 \\
$\mathbf{5}$ & Rp8.800 & 07.57 & 07.57 & 0 \\
\hline
\end{tabular}

Pada Tabel 4.7 maka didapatkan nilai rata-rata pada hasil percobaan notifikasi Short Message Service (SMS) adalah sebesar 0,6 detik. Sehingga dapat disimpulkan bahwa Notifikasi SMS tersebut dapat bekerja dan berfungsi dengan sagat baik dalam mengirim SMS dengan cepat pada saat biaya listrik sudah melebihi target.

\section{Pengujian tampilan pada aplikasi smartphone}

Pembuatan Aplikasi Smartphone untuk memonitoring hasil pembacaan sensor menggunkan software Android Studio 4.0.0 . Aplikasi Smartphone tersebut diberi nama SKRIPSIMUZ. Pengujian tampilan pada aplikasi smartphone bertujuan untuk membandingkan tampilannya dengan realtime pada simulasi di serial monitor. Nilai yang diambil adalah pembacaan kWH pada aplikasi smartphone.

Tabel 4.8 Hasil Pengujian Tampilan pada Aplikasi SKRIPSIMUZ

\begin{tabular}{ccccc}
\hline $\begin{array}{c}\text { Percobaan } \\
\text { ke- }\end{array}$ & $\begin{array}{c}\text { Serial Monitor } \\
(\mathbf{k W H})\end{array}$ & $\begin{array}{c}\text { SKRIPSIMUZ } \\
(\mathbf{k W H})\end{array}$ & $\begin{array}{c}\text { Selisih } \\
(\mathbf{k W H})\end{array}$ & Akurasi \% \\
\hline $\mathbf{1}$ & 0,74 & 0,74 & 0 & 100 \\
$\mathbf{2}$ & 0,74 & 0,74 & 0 & 100 \\
$\mathbf{3}$ & 0,75 & 0,75 & 0 & 100 \\
$\mathbf{4}$ & 0,76 & 0,76 & 0 & 100 \\
$\mathbf{5}$ & 0,77 & 0,77 & 0 & 100 \\
\hline
\end{tabular}

Pada Tabel 4.8 maka didapatkan nilai rata-rata akurasi antara Aplikasi SKRIPSIMUZ dan Serial Monitor adalah sebesar $100 \%$. Sehingga dapat disimpulkan bahwa SKRIPSIMUZ dapat bekerja dan berfungsi dengan sangat baik dalam menampilkan data.

\section{Pengujian perhitungan biaya pemakaian energi listrik}

Pengujian Perhitungan Biaya Pemakaian Energi Listrik ini bertujuan untuk mengetahui bahwa alat dapat memberikan informasi biaya pemakaian listrik sesuai dengan Tarif Dasar Listrik (TDL) PT.PLN (Persero) yang terdapat pada Persamaan 1[3].

Cost $=$ Jumlah konsumsi energi .Tarif dasar listrik (49)

Dimana:

Jumlah konsumsi energi (kWH)Tarif dasar listrik (Rupiah) 
Tabel 4.9 Hasil Pengujian Perhitungan Biaya

\begin{tabular}{cccccc}
\hline $\begin{array}{c}\text { Percobaan } \\
\text { ke- }\end{array}$ & $\begin{array}{c}\text { Jumlah } \\
\text { Konsumsi } \\
\text { Energi } \\
\text { (kWH) }\end{array}$ & $\begin{array}{c}\text { Biaya yang } \\
\text { ditampilkan } \\
\text { pada alat } \\
\text { (Rupiah) }\end{array}$ & $\begin{array}{c}\text { Biaya sesuai } \\
\text { perhitungan } \\
\text { Matematis } \\
\text { (Rupiah) }\end{array}$ & $\begin{array}{c}\text { Selisih } \\
\text { (Rupiah) }\end{array}$ & $\begin{array}{c}\text { Akurasi } \\
\mathbf{\%}\end{array}$ \\
\hline $\mathbf{1}$ & 0,74 & 7350 & 7400 & 50 & 99,32 \\
$\mathbf{2}$ & 0,74 & 7440 & 7400 & 40 & 99,45 \\
$\mathbf{3}$ & 0,75 & 7540 & 7500 & 40 & 99,45 \\
$\mathbf{4}$ & 0,75 & 7650 & 7600 & 50 & 99,32 \\
$\mathbf{5}$ & 0,77 & 7700 & 7700 & 0 & 100 \\
\hline \multicolumn{7}{c}{ Rata-rata } \\
\hline
\end{tabular}

Pada Tabel 4.9 didapat nilai rata-rata akurasi percobaan antara Aplikasi SKRIPSIMUZ dan Serial Monitor adalah sebesar 99,508\% dan nilai rata-rata selisih perbedaan percobaan perkiraan biaya sebesar 36. Sehingga dapat disimpulkan bahwa SKRIPSIMUZ dapat bekerja dan berfungsi dengan sangat baik dalam perhitungan perkiraan biaya pemakaian energi listrik.

\section{KESIMPULAN}

Alat dapat menunjukan informasi Tegangan, Arus, Daya , dan Jumlah Konsumsi Energi (Hasil Pengujian 4.3.1) dan dapat memberikan informasi tentang Perkiraan Biaya Energi Listrik (Hasil Pengujian 4.3.4) serta dapat memberikan Notifikasi Short Message Service (SMS) pada ponsel pengguna ( Hasil Pengujian 4.3.2) sesuai dengan yang diharapkan. Sensor Eastron SDM230 Modbus cukup Efektif dalam mengukur satuan listrik mulai pada objek atau pompa air (beban lstrik) dengan rata rata presentasi akurasi sebesar 98,704 \% pada pengukuran Tegangan, $39,88 \%$ pada pengukuran Arus, 53,333\% pada pengukuran jumlah konsumsi energi, dan 26,141 \% pada pengukuran Daya. Pada Notifikasi Short Message Service rata rata kecepatan pengiriman dengan diterimanya notifikasi sebesar 0,6 detik. Jumlah Konsumsi Energi Listrik yang ditampilkan pada Aplikasi Android SKRIPSIMUZ memiliki rata rataakurasi sebesar 100\% dan Perkiraan Biaya Listrik sebesar 99,508 \%. Hal tersebut membuktikan bahwa Aplikasi Android yang dibuat dapat berfungsi dan bekerja dengan sangat baik. Beberapa pengujian memeiliki akurasi yang yang rendah yang mungkin disebabkan oleh alat ukur perbandingan yang memiliki kondisi kurang baik.

\section{REFERENSI}

[1] D. Risqiwati, "Rancang Bangun Sistem Monitoring Listrik Prabayar dengan Menggunakan Arduino Uno," Kinetik, vol. 1, no. 2, 2016, doi: 10.22219/kinetik.v1i2.16.

[2] G. Herandy, T. Elektro, U. N. Surabaya, T. Elektro, and U. N. Surabaya, "MONITORING BIAYA DAN PENGUKURAN KONSUMSI DAYA LISTRIK BERBASIS ARDUINO MEGA2560 MENGGUNAKAN WEB," no. V, 2019.

[3] Lifepal.co.id, "Begini Lho Cara Menghitung Tarif Listrik yang Benar.” p. 1, 2018, [Online]. Available: https://lifepal.co.id/media/begini-lho-cara-menghitung-tarif-listrik-benar/. 